\title{
PERSPECTIVAS DA RESILIÊNCIA NO EMPREENDEDORISMO FEMININO
}

TACELI, Izabel Cristina ${ }^{1}$

SANTOS, Geisiane Rodrigues dos ${ }^{2}$

RESUMO: $\mathrm{Na}$ seara da psicologia organizacional, a resiliência vem sendo tratada fundamentalmente em face das perspectivas, ações e possíveis avanços que pode ofertar ao contexto empresarial. Assim, o objetivo principal deste artigo é o de pensar o constructo da resiliência, aplicando-o ao empreendedorismo feminino contemporâneo. Para a elaboração da pesquisa, os procedimentos metodológicos adotados foram os da revisão bibliográfica, combinada com a pesquisa qualitativa. A hipótese de trabalho foi a de que o processo adaptativo poderia influenciar os debates e a expansão do empreendedorismo feminino. Este fato nos permitiu investigar algumas características desta resiliência que fossem capazes de formar o comportamento empreendedor da mulher, ao mesmo tempo em que contribuintes para facilitar ou dificultar a inclusão feminina aos contextos permeados pela figura masculina. A temática se torna ainda mais relevante, visto que a resiliência tem um papel proeminente para a superação das condicionantes de alteridade das mulheres, quando elas se veem diante da intensa competitividade em diferentes postos no mercado de trabalho. Como resultados de nosso estudo, aponta-se que a compreensão efetiva da resiliência e do papel da mulher dentro do cenário organizacional exige mudanças profundas de cunho social, econômico e cultural, pois o ser humano pode ser entendido como um tipo de sujeito que se faz em função de suas relações no mundo e, com o mundo, constrói a sua história.

PALAVRAS-CHAVE: Comportamento, características empreendedoras, empreendedorismo feminino, resiliência

ABSTRACT: In the field of organizational psychology, resilience has been treated fundamentally in view of the perspectives, actions and possible advances that can affect the business context. Thus, the main objective of this article is to think about building resilience, applying it to contemporary female entrepreneurship. For the preparation of this research, the methodological procedures adopted were those of bibliographic review, combined with a qualitative research. The working hypothesis was an adaptive process that could influence debates and expand female entrepreneurship. This fact allowed us to investigate some characteristics of this resilience that were capable of forming the entrepreneurial behavior of women, while contributing to facilitate or hinder female inclusion in the contexts permeated by the male figure. The theme becomes even more relevant, since resilience has a prominent role in overcoming the conditions of otherness of women, when they are faced with intense competition in different positions in the labor market. As a result of our study, it is pointed out that the effective understanding of the resilience and role of women within the organizational scenario requires profound social, economic and cultural changes, as the human being can be understood as a type of subject that is made in function of its relations in the world and, with the world, it builds its history.

KEYWORDS: Behavior, entrepreneurial characteristics, female entrepreneurship, resilience

\footnotetext{
${ }^{1}$ Mestre em Psicologia pela Universidade Católica de Brasília e docente do Colégio Técnico e Faculdade - UNITERP. Membra do Grupo de Pesquisa Direito e (IN) tolerância Religiosa e do Grupo de Pesquisa Internacional e Grupo de Pesquisa Estudos Luso Brasileiro do Audiovisual - CNPq/UEMG Universidade do Estado de Minas Gerais.

${ }_{2}^{2}$ Mestre em Matemática pela Universidade Cruzeiro do Sul e docente da Universidade do Estado de Minas Gerais - UEMG/Frutal.
} 


\section{INTRODUÇÃO}

Os cenários e econômicos em constante mutação, demandam dos pesquisadores a instituição de espaços de debate em que se discutam e se refaçam a fundamentação do empreendedorismo. Assim, o mundo pode se abrir mais facilmente para a compreensão e importância do empreendedorismo em novos contextos, ao mesmo tempo em que permite ao cientista social buscar novas formas de desenvolver, na sociedade, valores os quais essencialmente as pessoas sejam representadas por meio de suas lideranças empreendedoras.

O que se pergunta, em princípio, é o que levaria as mulheres a assumirem papeis de liderança no universo do empreendedorismo, dentro de um ambiente pautado por extrema hostilidade à sua presença? Outra questão que surge deste mote é a de sabermos de onde emana a força da mulher para superar estes e outros obstáculos? Em suma, é de muita importância que compreendamos como a resiliência social, cultural, organizacional é aliada das mulheres empreendedoras.

Neste sentido, o entorno da questão da resiliência feminina no mercado de trabalho também gira ao redor do entendimento do termo "empreendedorismo". Inicialmente, vemos que não se trata de uma disciplina acadêmica como a Psicologia, a Sociologia, a Física ou a Matemática, mas sim de um domínio particular, pelo fato de não existir um consensual científico robusto para esclarecer a natureza das relações que aqui se propõem.

Por outro lado, observa-se um conjunto de fatores práticos que são baseados nas performances geradoras de riquezas, desenvolvimento e crescimento em sociedades que se utilizam desta prática. É assim que autores como Baggio e Baggio (2014, p. 27) ou Hisrich \& Peter (2004) ponderam sobre dois destes aspectos: o do desenvolvimento da teoria do empreendedorismo; e, o da terminologia empreendedora.

No entanto, ainda na Idade Média, e estendendo-se até o ano de 1985, vimos ocasionalmente acontecer uma preocupação em se construir uma definição mais exata sobre o que seria o empreendedorismo. Daí, é que emerge a ideia de que empreendedorismo é um processo que implica na 
criação de algo que seja diferente, capaz de gerar valor, e que demande dedicação de tempo e de esforço necessários ao sucesso da ideia, requisitando dos atores que assumam os riscos financeiros, psicológicos e sociais correspondentes aos processos e, consequentemente, sujeitos recebedores das recompensas, da satisfação econômica e do prestígio pessoal.

E foi também, em meados dos anos 1980, que o empreendedorismo, e seus desdobramentos no empreendedorismo feminino, passou a ser objeto de estudos mais adensados, elevando-o a um patamar político e econômico de maior autoridade. Nessa perspectiva de construção conceitual e de diversificação das abordagens, é que se lê, que:

As principais teorias que abordam o empreendedorismo são: a teoria econômica e a teoria comportamentalista. A teoria econômica, também conhecida como schumpeteriana, demonstra que os primeiros a perceberem a importância do empreendedorismo foram os economistas. Estes estavam primordialmente interessados em compreender o papel do empreendedor e o impacto da sua atuação na economia. Três nomes destacam-se nessa teoria: Richard Cantillon, Jean Baptiste Say e Joseph Schumpeter (BAGGIO; BAGGIO, 2014, p. 27).

Porém, ao lado disso, se observa que na realidade os economistas preocupados com o empreendedorismo, não conseguiram criar uma ciência comportamentalista, voltando-se, por sua vez, aos aspectos organizacionais da circulação, da gestão e da produção de bens. Por sua vez, a essência da teoria comportamentalista passou a se referir diretamente aos especialistas do comportamento humano, isto é, aos psicólogos, aos psicanalistas, aos sociólogos, entre outros. Assim, importa salientar que:

Um dos primeiros autores desse grupo a demonstrar interesse foi Max Weber. Ele identificou o sistema de valores como um elemento fundamental para a explicação do comportamento empreendedor. Via os empreendedores como inovadores, pessoas independentes, cujo papel de liderança nos negócios inferia uma fonte de autoridade formal. Todavia, o autor que realmente deu início à contribuição das ciências do comportamento foi David C. McClelland (BAGGIO; BAGGIO, 2014, p. 28). 
Sendo, portanto, um dos principais autores a tratar do papel do homem e sua relação com os negócios na sociedade, viu que sua contribuição poderia ser importante para elevar os indicadores econômicos, além de McClelland, indicamos que outros pesquisadores se aprofundaram na busca compreensão do empreendedorismo como fonte das realizações pessoais. Mas, cabe destacar, que isto não está atrelado de modo incorruptível ao sucesso dos empreendedores especificamente.

Conjuntamente, portanto, economistas e comportamentalistas uniram seus esforços para ampliarem as características que fazem parte do comportamento empreendedor. Visto que o referencial teórico dos economistas pautou-se nos aspectos voltados para a inovação, enquanto que os comportamentalistas focaram nas atitudes, na criatividade e na intuição. Sendo assim, é salutar afirmar, que "o empreendedor apresenta um papel particular, isto é, ele diferencia a função empreendedora e a função capitalista" (BAGGIO; BAGGIO, 2014, p. 28).

Nota-se que deste "epicentro" surgem novos paradigmas que compõem e renovam os cenários, trazendo abordagens diferenciadas, enredando fatores socioeconômicos, como aquele visto na "Teoria da Mudança", a partir da qual se define como metodologia, "um conjunto de diretrizes, que orientam os empreendedores sociais a concretizarem o seu objetivo último - mudança social" e ainda prescreve que "os empreendedores sociais fazem um mapeamento dos requisitos e condições necessárias para o seu fim, e desenvolvem indicadores para medir os progressos e resultados, avaliando assim o desempenho da sua iniciativa de mudança" (BAGGIO; BAGGIO, 2014, p. 30).

Nesse contexto, enfim, notou-se que as mulheres estariam cada vez mais ocupando o seu lugar no domínio do empreendedorismo, apresentando aos teóricos do tema especificidades, cujas características se faziam recair sobre o volume dos negócios, criando novas oportunidades e novos postos de trabalho na sociedade. 


\section{EMPREENDEDORISMO NA CONTEMPORANEIDADE}

No Brasil existem alguns órgãos e instituições que trabalham, medem, analisam e defendem as ações voltadas para o empreendedorismo. Dentre elas, evocamos o SEBRAE (Serviço Brasileiro de Apoio às Micro e Pequenas Empresas), e o IBPQ (Instituto Brasileiro de Qualidade e Produtividade), além de universidades que contam com projetos de extensão, pesquisas e também as empresas que se fazem engajar na ampliação e no reconhecimento de todos os modelos de negócios por todo o país.

A ideia aqui é a de verificar o panorama científico de algumas pesquisas sobre o tema. E, nesse espectro, observamos um programa de pesquisas, com colaboradores nacionais e internacionais, intitulado GEM Global Entrepreneurship Monitor, que apresenta uma proposta:

[...] baseada em avaliações sobre o nível de atividade empreendedora nacional para todos os países participantes, envolvendo uma exploração do papel do empreendedorismo no crescimento econômico nacional, revelando a riqueza das características associadas com a atividade empreendedora [...] (GEM, 2018, p. 07).

O GEM, com sede no Brasil e no exterior, foi criado a partir de instituições renomadas como a "Business School" (Inglaterra) e o "Babson College" (Estados Unidos). Desde então (aproximadamente isso remonta ano de 1999), anualmente são apresentados relatórios que elucidam os atores sociais, políticos e econômicos sobre as principais características atinentes ao empreendedorismo.

Essa extensa trajetória de 20 anos do GEM, começou com a participação de dez países. Ao longo desse tempo, mais de 100 outros se integraram em regime de revezamento e, em 2018, firmam-se em número de 49. Estes, por sua vez, manifestam a compreensão de que "a maior e mais complexa pesquisa cooperativa sobre empreendedores e seus empreendimentos no mundo", é aquela que se propõe a estudar o ambiente, "para criar e manter novos negócios". Sua eficácia será mensurável, na medida em que se "apura a percepção com que cada sociedade", em cada um dos 
países membros, "manifesta certo grau de compreensão sobre o empreendedorismo" (GEM, 2018, p. 07). Desse modo, reúnem-se informações com os seguintes resultados:

- O primeiro processo consiste na coleta de dados junto a uma amostra representativa da população brasileira de indivíduos, entre 18 a 64 anos, buscando identificar as atitudes, as atividades e as aspirações da população em relação ao empreendedorismo. Esse processo é chamado de "Pesquisa com a População Adulta" ou simplesmente APS.

- O segundo processo de coleta de dados busca avaliar as condições objetivas para o desenvolvimento de atividades empreendedoras e para a criação de novos negócios no país. Essa sondagem é conduzida por meio de entrevistas com profissionais - por intermédio de pesquisas denominadas de "especialistas" - que são detentoras de conhecimento e experiência expressivos na temática do empreendedorismo e suas variantes. Trata-se de uma amostragem intencional, em que os especialistas selecionados são instados a identificar e a avaliar os fatores que contribuem e os fatores que limitam a atividade empreendedora no país. Esse processo é chamado de "Pesquisa com Especialistas", ou simplesmente NES (GEM, 2018, p. 07).

O estudo proposto pelo GEM retrata o contexto do empreendedorismo de forma parcial. Todavia, é útil, pois retrata aspectos multifacetados do empreendedorismo, instituindo análises metodológicas aprofundadas que se fazem constar numa publicação denominada Empreendedorismo no Brasil 2018. Tema este que não detalharemos, visto que o foco desse artigo é observar a resiliência feminina no empreendedorismo nos dias atuais.

Outro ponto importante da pesquisa do GEM é que ela entrevista especialistas nacionais, selecionados intencionalmente. Dentre eles estão profissionais, acadêmicos, agentes do setor público ou privado, empreendedores experientes, incluindo-se, assim, atores que apresentem uma visão dos negócios desenvolvidos no Brasil, a fim de obter melhores respostas às condicionantes que levam a empreender no país.

Utilizando-se de uma coleta de dados, chamada de NES - National Experts Survey, verifica-se como "o financiamento para os novos negócios, políticas e programas governamentais de apoio ao empreendedorismo, 
educação e capacitação, desenvolvimento tecnológico e infraestrutura entre outros tantos aspectos ligados ao tema", podem e precisam acontecer em todos os ambientes geradores de negócios (GEM, 2018, p. 21).

Para estes especialistas supracitados, foram apontados alguns resultados:

Os principais fatores apontados estão relacionados com as "políticas governamentais" $(73,8 \%)$, sendo os aspectos ligados aos tributos e à burocracia ainda os mais lembrados. Em segundo lugar, no número de menções apresentadas, está o fator "apoio financeiro". Para 42,9\% dos especialistas, a restrição de crédito ao empreendedor, aliada à dificuldade para acessar os recursos financeiros, quando disponíveis, representam uma importante barreira para o empreendedor no Brasil. Em seguida, é citado por $40,5 \%$ dos especialistas, o fator "educação e capacitação", que pode limitar as possibilidades de se alcançar um empreendedorismo com mais impacto econômico e social, dada a formação geral e técnica que os empreendedores recebem, dificultando, assim, a lida com os negócios (GEM, 2018, p. 22).

Por conseguinte, podemos salientar que os dados apresentados pelos especialistas não se tratam de planos a serem aplicados em curto prazo, e sim, são sugestões, ou mesmo provocações, que podem ser implementadas ou que já precisam ser aperfeiçoadas no contexto de negócios no Brasil. Assim, à medida que ocorrem mudanças contínuas nos cenários corporativos, os estudos avançam paralelamente, construindo saberes adicionais ao assunto.

\section{EMPREENDEDORISMO FEMININO}

A ideia central em análise é a de investigar a natureza do papel feminino no empreendedorismo. Num panorama enrijecido pela práxis dos negócios, a mulher agrega ao ambiente mais sensibilidade, sendo ela um ser que, por natureza, é intuitivo e, neste caso, a mulher teria nascido, então, com instinto natural para empreender e para se desdobrar em vários papeis sociais.

Além disso, a mulher sabe aproveitar as habilidades, antes tidas como domésticas, para gerar renda: trabalhos manuais, artesanato, limpeza em geral, bordar, costurar, cozinhar, dentre outras coisas. Estes e outros afazeres, não raro, são transformados em negócios. 
Autores como Candaten, Zanatta e Trevisan (2016, p. 03) analisam o ponto de vista de Lindo (2004) sobre a participação das mulheres no mercado de trabalho, sobretudo as que são donas de casa. Neste paradigma, vê-se que, num certo recorte temporal, houve crescimento considerável da inserção feminina, fenômeno que pode ser atribuído ao perfil inato do sujeito feminino, à forma de liderarem afetivamente as pessoas, crianças, os idosos, visto que elas tendem a se adaptarem mais rapidamente a diversas situações.

Tais características que são a cada dia mais demandadas no mundo empresarial, atingem um nível esperado e desejável no âmbito do trabalho e no desenvolvimento de carreiras. Por conseguinte, o entrecruzar dos papeis femininos embrincam-se aos estudos de cunho científicos, fazendo surgir relevantes contribuições sobre a participação da mulher no mercado de trabalho.

Esta intervenção feminina no contexto do empreendedorismo é descrita por estudiosos como Cassol (2006); Marasea e Andrade (2006) apud Franco (2014). E, posteriormente, noutros estudos, com foco no empreendedorismo (CARVALHO NETO; TANURE; ANDRADE, 2010). E, ainda, nas pesquisas de Grzybovski et al (2002), que deram importância ao fator diferencial que a mulher trouxe ao ambiente dos gestores.

Assim sendo, "a mulher constrói um sentimento de comunidade, através do qual une os membros da organização, conseguindo criar um laço que faz com que aprendam e acreditem uns nos outros". Aí, se destacam a forma das mulheres se comunicarem e ao mesmo tempo demandar "informações" pertinentes ao ambiente de trabalho, como exposto pelos autores nesse estudo e, em particular (GRZYBOVSKI; BOSCARIN; MIGOTT, 2002).

Já, Loureiro, Costa e Freitas (2012), enfatizam o papel que a mulher ocupa na sociedade, na família, no casamento, com os filhos, nas tarefas da casa e nas responsabilidades do lar. Especificamente, as enquadra em sua relação com o marido (CARVALHO NETO, TANURE, ANDRADE, 2010), acentuando-se, nisso, que as mulheres são multifacetadas, ou seja, conseguem executar diversas tarefas simultaneamente. 
Os autores Candaten, Zanatta e Trevisan (2016) analisam ainda o ponto de vista de autores (ZIBETTI; PEREIRA, 2010), os quais se referem à questão da "inserção da mulher em um espaço que antes era somente masculino", o que acabou por fazer com que ela "anexasse às funções domésticas o trabalho fora de casa, sobrecarregando-a com uma dupla jornada".

Além disso, a mulher sofre diariamente uma dura competitividade em relação aos homens, disputando vagas que, no decorrer do tempo, foram ocupadas por eles. Sem dizer que quanto ao aspecto relacionado ao gênero as colocaram sempre em posição de desvantagem no ambiente de trabalho, focando-se em status como os do "estado civil, da maternidade, do assédio sexual e moral" (LAGES; DETONI; SARMENTO, 2005).

Desse modo, na contemporaneidade é importante observar o papel empreendedor da mulher e o desbravamento que ela vem alcançando no cenário empreendedor. Este posicionamento vem se equilibrando com o da participação masculina, e vem se fortalecendo devido à capacidade dela em resistir às adversidades, lidar com situações conflitantes, ao seu perfil proeminente criativo e empreendedor, que as remete a um dom peculiar do feminino.

Porém, cabe ressaltar, a característica empreendedora é uma peculiaridade válida tanto para o sexo masculino quanto para o feminino. E nisso, o desenvolvimento dessa competência independe da profissão, de classe social e do lugar onde se vive. Envolve, por sua vez, um conjunto de características que vão desde a aptidão para assumir riscos, à persistência e ao comprometimento, ou mesmo em saber buscar informações e estabelecer metas. Por fim, saber lidar com o sucesso e sobreviver no mundo competitivo do mercado de trabalho é condição sine qua non, que move as empreendedoras e, também os empreendedores.

\section{PERFIL FEMININO MULTIFACETADO}

A mulher, em sua trajetória, percorreu um processo social gradativo, por vezes doloroso e adormecido ao longo da história. Todos os desafios 
enfrentados trouxeram à luz uma pessoa que empreende e busca renovar-se, libertando-a de toda submissão sofrida, galgando gradualmente os seus direitos, emergindo de um lugar de intenso silêncio para ser verdadeiramente ouvida e percebida pela sociedade.

E estes são mais do que dados oriundos da percepção pessoal ou coletiva. A ciência ratifica esse percurso nos dias de hoje, por meio de estudos relevantes voltados para a compreensão do feminino organizacional, fazendo despontar um novo olhar que conta um pouco da luta das mulheres quanto à sua inserção no mundo do trabalho.

Também neste sentido, é que Teixeira (2012, p. 97) afirma que a mulher incorporou na história corporativa global, um tipo de fluxo que pode ser descrito em etapas como estas:

- a mulher do início dos tempos;

- o papel da mulher no período colonial;

- a entrada da mulher no mercado de trabalho - a revolução industrial como marco impulsionador;

- o processo de evolução da mulher no mercado de trabalho;

- os marcos conquistados pelas mulheres ao longo da história;

- as mulheres que fizeram diferença na história;

- o perfil atual da mulher no mercado de trabalho;

- as diferenças de salários nos gêneros;

- as empresas que possuem mulheres como líderes; e,

- o que as empresas têm exigido dos novos profissionais.

E arremata esse histórico, dizendo que, a respeito do aspecto relacionado ao perfil empreendedor:

A visão de mercado e o perfil empreendedor feminino aparecem em larga escala, elas se mostram inovadoras e fazem um preparo maior que eles na hora de abrir um negócio, também conseguem lucrar sem estresse uma vez que em se tratando de franquias elas estão à frente 
lucrando mais que os homens pelo simples fato de não reclamarem das dificuldades em conseguir financiamento para suas empresas, e lutam até conseguir e serem bem sucedidas. A persistência e a perseverança tornam-se fatores decisivos nesse âmbito (TEIXEIRA, 2012, p. 116).

Tais aspectos postos em cotejamento demonstram os traços de uma função multifacetada que a mulher possui em toda a sua trajetória, sem dizer sobre os fatores de conciliação de seus múltiplos papeis na vida pessoal e profissional. Soma-se a estas características, verifica-se um grau aprofundado de persistência, o que, não raro, a leva a conquistar as metas estabelecidas.

Nessa perspectiva, Teixeira e Gama são autores que apresentam algumas definições em torno do empreendedorismo importantes:

As definições acerca do empreendedor são amplas e vêm sendo conceituadas por diversos estudiosos que contemplam a teoria desde 0 século XVII. Dado isso, é coerente ressaltar que esse fenômeno é multifacetado e não pode ser compreendido por uma única lógica. Entretanto, quando se refere à origem das definições do vocábulo, é pertinente reiterar que foi o economista Joseph Alois Schumpeter no século $X X$ que alcançou com êxito o significado de empreendedorismo (TEIXEIRA; GAMA, 2018, p. 01).

Dessa forma, as conceituações apresentadas dão contributos para melhor caracterizar o perfil necessário ao empreendedor, enfatizando que a inovação é um aspecto fundamental no âmbito organizacional, ou seja, descortina a capacidade de buscar novos produtos, serviços, gerando possibilidades econômicas e inovadoras, que partem do senso comum e estabelecem uma identidade que potencializa as oportunidades e promove importantes mudanças e transformações.

Nesse caso, independentemente do perfil ser do sexo masculino ou feminino, parte-se da premissa de "que a mulher empreendedora se enquadra nesse parâmetro, pois é perceptível que a mesma conquistou espaço significativo e continua progressivamente se fortalecendo no mercado" (TEIXEIRA; GAMA, 2018, p. 01). 
A mulher impacta significativamente a economia, levando-se em conta um conjunto de valores que impulsiona o crescimento e o desenvolvimento socioeconômico do país. Faz-nos crer nisso, o fato de que:

A assertiva é contundente, visto que os estudos mostram que no cenário brasileiro o aumento de mulheres que empreenderam superou 0 índice dos homens. Os dados indicam que, entre 2012 e 2015, cerca de $15,1 \%$ dos empreendimentos, com 3,5 anos de atividade pertenciam ao público feminino, o que, certamente, comprova que os empreendimentos femininos são crescentes. Nesse mesmo parâmetro, os dados concluíram que $51 \%$ dos empreendimentos iniciais também foram representados por mulheres, considerado uma progressão relevante, visto que as mesmas possuem características empreendedoras que contribuem para tornar as empresas mais sólidas e lucrativas (TEIXEIRA; GAMA, 2018, p. 01).

Diante disso, vale informar, que os resultados apresentados identificaram a feição da mulher empreendedora no Município de Rondon, no Estado do Pará. Ali, discutiram-se dois aspectos: a) se a atividade empreendedora surgiu de uma necessidade ou, se surgiu b) de oportunidade das mulheres analisadas. A pesquisa observou, ainda, a importância de se identificar as dificuldades e os desafios que as mesmas enfrentaram em relação ao mercado de trabalho, condições que, para este nosso estudo, foram de enorme valia, uma vez que alimentaram as fases iniciais de nossa revisão bibliográfica.

\section{RESILIÊNCIA FEMININA}

Dentre as problemáticas apresentadas em relação à mulher empreendedora estão sua condição feminina, as barreiras para alcançar cargos ocupados por homens, o mercado de trabalho e como fazer para conciliar a vida dentro e fora de casa. Resumidamente, sabe-se que se retomaram alguns pontos, mas, na prática, do dia a dia, muitos outros entraves surgem.

Vale lembrar, que, quando um membro de sua família ou ela mesma adoece, aí a configuração se desacerta, ou quando não consegue uma vaga na creche para os filhos, pois, muitas vezes, a mulher não conta com os familiares para auxilia-la. Diante de adversidades como estas, aflora a mulher resiliente: 
Com origem no latim, a palavra resilio designa o retornar a um estado anterior (BARLACH et al., 2008). O termo resiliência é aplicado em diversas áreas do conhecimento: desde a ecologia, sociologia, economia, psicologia individual e organizacional, gestão da cadeia de fornecimento, gestão estratégica, gestão de riscos, gestão da engenharia da segurança (BHAMRA, DANI, \& BURNARD, 2011), Erol et al. (2010), física, engenharia e aos sistemas da informação. O termo foi popularizado em 1973, por Holling, com um estudo aplicado à resiliência ecológica: "Resilience and stability of ecological systems" (BHAMRA et al., 2011; SALGADO, 2013, p. 07).

Tendo em vista a abrangência da aplicabilidade da resiliência e perpassando o conceito por diversas áreas da ciência, inclusive nas áreas da administração e da psicologia e, em específico, quando se trata dos fenômenos no contexto organizacional, optamos por parafrasear Salgado:

Waller (2001), citado por Barlach et al. (2008) apresenta uma definição de resiliência como "um produto multideterminado e sempre mutável, de forças que interagem num determinado contexto ecossistémico". $\mathrm{Na}$ perspectiva da psicologia, a resiliência explica fenómenos psicossociais que se referem a indivíduos, grupos ou organizações que ultrapassam ou transcendem situações adversas. A psicologia explica a mobilização de recursos psicossociais para enfrentar roturas e situações de tensão características da modernidade (BARLACH et al., 2008; SALGADO, 2013, p. 08).

No contexto do mundo dos negócios, as pessoas constantemente enfrentam situações conflituosas, muitas vezes, quando se trata do crescimento sem precedentes das exigências advindas do mercado de trabalho, tornando as relações de trabalho mais adversas, provocando demasiada competitividade, levando a conflitos e frustrações no dia a dia empresarial. Daí, a importância da resiliência para que o sujeito se adapte às inúmeras situações enfrentadas diariamente, como aquelas apontadas por Salgado, enfatizando-se a opinião de Erol et al. (2010) que, por conseguinte, compilam ideias de distintos autores:

- (1) A capacidade do sistema em responder de forma adaptativa a um evento perturbador de forma a evitar perdas; e, 
- (2) A capacidade de se recuperar rapidamente, num período de tempo e com custos aceitáveis; permite que o sistema continue a funcionar de forma a atingir os objetivos, mantendo o controlo sobre o funcionamento e a estrutura, traduzindo-se numa capacidade de auto-organização, de aprendizagem e adaptação (SALGADO, 2013, p. 08).

Vimos, então, que muitos autores versam sobre a resiliência, trazendo características peculiares, porém, cremos que seja importante analisar a forma como cada indivíduo age e reage para se adaptar e, ao lado daquele que é dotado de maior capacidade resiliente, o primeiro passa a se adaptar positivamente, rapidamente, evitando perdas e atingindo objetivos e metas de forma mais equilibrada, pois desenvolve maior segurança em si mesmo, elava sua própria autoestima e melhora o ambiente de trabalho.

Salgado (2013) cita Bhamra et al. (2011), fazendo ampliar a ideia de resiliência. Assim, traz contribuições às abordagens tradicionais, indicando "15 definições do conceito, aplicáveis aos sistemas físicos, aos sistemas ecológicos, aos sistemas sociais e ecológicos, à psicologia, à gestão de desastres, ao indivíduo, às organizações e à engenharia", dentre as quais, 03 definem a resiliência organizacional:

- A Resiliência Organizacional (traduzido de BHAMRA et al., 2011) é a qualidade fundamental para responder, de forma produtiva, a uma mudança significativa que perturba o padrão esperado, sem a introdução de um longo período de comportamentos regressivos.

- Horne and Orr (1998) aponta que a Resiliência refere-se à capacidade de contínua reconstrução.

- Hamel and Valikangas (2003) afirmam que a Resiliência transmite a ideia de que as propriedades de adaptação dizem respeito às exigências do ambiente e que a natureza de sua capacidade consiste em gerir as variabilidades ambientais (McDONALD, 2006).

De forma resumida, Salgado (2013) versa sobre Dalziell \& McManus (2004), esclarecendo que: 
Existem dois tipos de resiliência: aquela que se foca na velocidade com que a organização recupera de uma perturbação e volta ao estado normal, foca-se na eficiência do funcionamento e nos processos; (ii) aquela que varia de acordo com a quantidade de perturbações que a organização pode absorver antes da sua reestruturação, o que implica processos flexíveis que permitam manter o funcionamento perante um grande número de perturbações (ainda que não signifique o aumento da eficiência) (SALAGADO, 2013, p. 12).

Portanto, vemos que as definições mencionadas levam o leitor a uma melhor compreensão do constructo da resiliência, para a qual implica adotar uma perspectiva multissetorial, uma vez que se trata de um conceito do domínio da psicologia, da psicopatologia, da psicanálise, da sociologia, da psiquiatria e da pediatria, entre outros.

A conceituação do tema em questão é de suma importância, ainda, para que se elabore uma compreensão do fenômeno da resiliência em relação às variáveis do comportamento humano, que não é tema do presente artigo, porém, importa ressaltar que o assunto poderá ser analisado com maior profundidade em diferentes nuances do saber.

\section{ASPECTOS METODÓLOGICOS}

Uma investigação foi proposta por Salgado (2013, p. 60), na qual se utilizou de um estudo de caso, objetivando colher informações baseadas no constructo da resiliência organizacional, especificamente de uma empresa que atua em Portugal, na área da hotelaria e turismo e, desse modo, se puderam identificar parâmetros de desenvolvimento de serviços de informação. Trata-se de um trabalho de cunho qualitativo, com um sujeito e uma pequena amostra de participantes, num dado contexto específico, combinado com um estudo descritivo e aprofundado, ilustrando o entendimento da resiliência dentro de uma organização. Neste sentido:

O estudo de caso é uma "tentativa de abranger as características mais importantes do tema que se está a pesquisar" (CARVALHO, 2000) e "toma por objeto um fenómeno contemporâneo situado no contexto da vida real" (KETELE \& ROEGIERS, 1993). O estudo de caso permite responder às questões "como?" e "porquê?" e é utilizada a "lógica 
indutiva - raciocínio a partir de termos mais específicos para mais gerais" (Colorado State University, n.d.). O estudo de caso aqui desenvolvido suporta-se na realização de entrevistas com responsáveis da organização em áreas funcionais consideradas críticas ao desenvolvimento da resiliência. Este estudo é usado para perceber um fenómeno ainda pouco investigado e pretende orientar o desenvolvimento de estudos futuros sobre a resiliência organizacional (SALGADO, 2013, p. 60).

Nesse estudo, a fundamentação investigativa empregou uma entrevista, objetivando obter informações sobre fatos ou representações, quanto a um determinado tema, respeitadas as devidas limitações, visto que os entrevistados poderiam não informar de modo preciso ou mesmo o entrevistador não interpretar claramente os dados obtidos.

Observou-se, em relação ao tema da resiliência nas organizações, que foram identificados "três grandes áreas de intervenção: gestão estratégica e operacional, gestão de recursos humanos e gestão dos sistemas de informação" (SALGADO, 2013, p. 61).

Para enquadrar o mercado de atuação da empresa, utilizaram-se documentos com dados estatísticos relativos à evolução da atividade no setor da hotelaria e, também, do mercado de atuação, da evolução do mercado da empresa e outros.

Sendo assim, os resultados obtidos em um Boletim Mensal de Estatística, datado de Fevereiro de 2013, publicado pelo Instituto Nacional de estatística, concluiu que:

Os resultados desta pesquisa mostram que os valores pessoais mais valorizados são o espírito de equipe $(67,1 \%)$ e o gosto pela aprendizagem (58\%), o sentimento de competência é o valor pessoal com menor peso $(32,2 \%)$. Os valores organizacionais que os colaboradores identificaram como tendo mais importância, são a conformidade $(79 \%)$ e o prestígio $(78,8 \%)$, e aquele com menor importância é o bem-estar (62,6\%) (SALGADO, 2013, p. 81).

Isto posto, mostra-se que, para se desenvolver a resiliência organizacional da empresa em estudos teóricos, seria necessário identificar quais as atividades críticas, objetivando acompanhar os processos e práticas que levem a maior segurança dos serviços, ou seja, "importa que a empresa 
construa cenários e identifique como é que pode lidar e o que pode fazer perante essas eventuais situações perturbadoras" (SALGADO, 2013, p. 90).

No sentido de compreender a conceituação de resiliência organizacional e as características identificadas, concluímos que a organização em pauta é pouco resiliente, visto que ela cumpre apenas parte do que se espera e ainda apresenta poucas características que a permitam ser mais resilientes quanto ao atendimento de seus colaboradores. Em tal conjuntura, a empresa avalia que:

É importante que a organização desenvolva as relações intra e interorganizacionais, isto é, as relações no interior da organização e entre os seus recursos humanos, operações e processos de trabalho (coesão) e entre a organização e os parceiros, fornecedores e clientes (conectividade). Importa que a organização avalie o seu estado atual, as suas capacidades, ou seja, desenvolva o autoconhecimento e também a capacidade de aprender com os erros e incidentes passados, de forma a desenvolver a capacidade de renovação e aprendizagem (SALGADO, 2013, p. 92).

Ao contrário do que se esperaria, a empresa só poderá desenvolver melhor a questão da resiliência organizacional quando demonstrar confiabilidade. Noutros termos, quando ela adquirir a capacidade de manter a segurança, corrigir seus próprios erros, atuando em observância ao estado atual e às ameaças potenciais.

\section{TRATAMENTO DOS DADOS}

Em comparação com 0 estudo do presente artigo sobre 0 empreendedorismo feminino, a pesquisa realizada na Europa aqui citada, revela características semelhantes quanto a alguns fatores, tais como o espírito de equipe, o qual é valorizado pela mulher, que prima pela integração das pessoas, o aspecto de gostar de aprender e renovar-se constantemente e demais.

Por outro lado, vimos que os valores pessoais são bastante relevantes para as mulheres empreendedoras, diferentemente do que apontou o estudo 
europeu. Por sua vez, o quesito da resiliência apresentado pela empresa portuguesa consiste no fato de ser pouco resiliente, em discrepância com a mulher empreendedora no Brasil, que demonstra maior resiliência pelo fato de que precisa enfrentar desafios constantes, mesmo sob discriminação em função de sua condição feminina.

Por fim, vê-se que as mulheres empreendedoras apresentam capacidade de se adaptar a muitas situações adversas, quer seja no trabalho ou fora dele, demonstrando serem bem mais flexíveis, por desenvolverem muitas tarefas ao mesmo tempo.

\section{CONCLUSÕES}

Este artigo teve como objetivo propor um recorte em torno da compreensão da resiliência feminina no contexto do empreendedorismo, observando que, ao longo da história, a mulher viveu uma parte significativa de sua vida submissa aos padrões familiares e de uma sociedade desigual, em que ainda é nutrida pelo machismo.

O perfil da atual mulher no mundo do empreendedorismo tende a coloca-la em relevantes patamares de conquista, visto que, ao longo dos tempos, ocorreram marcos importantes nas lutas de gênero. E, foi justamente a partir da Revolução Industrial, que um novo cenário deste tipo pôde ser observado, frente às novas tecnologias, às constantes mudanças no perfil do mercado de trabalho. Desse modo, a mulher passou, então, a se projetar de forma diferenciada, experimentando maior liberdade em suas escolhas profissionais, e maior independência para eleger os fatos que não faziam parte de sua realidade.

Principalmente em relação ao processo de ascensão no mercado de trabalho, a atuação da mulher pode ser percebida em diferentes profissões, que antes só eram ocupadas por homens, como engenheiras, caminhoneiras, advogadas, entre outras. Isto se dá, pois, incansavelmente a mulher vem se profissionalizando e buscando aperfeiçoamento em áreas que antes eram predominantemente do sexo masculino. 
Ademais, o mercado de trabalho passou a valorizar nelas, qualidades como a liderança, o trabalho em equipe, além de serem suficientemente assertivas e intuitivas.

Nota-se que persiste uma luta dos gêneros em nossa sociedade, no mundo empreendedor, tendo em vista o processo de submissão experienciados por parte da mulher durante décadas. Atualmente, a luta pela igualdade tem sido mais restrita à área salarial, não só em países subdesenvolvidos, quanto desenvolvidos. Porém, com a evolução da mulher na contemporaneidade e, principalmente, devido à sua característica resiliente, elas estabelecem caminhos futuros melhores que os de hoje. 


\section{REFERÊNCIAS}

BAGGIO, Adelar Francisco \& BAGGIO, Daniel Knebel. Empreendedorismo: Conceitos e Definições. Rev. de Empreendedorismo, Inovação e Tecnologia, 1(1): 25-38, 2014. ISSN 2359-3539. Disponível e: http://www.bibliotekevirtual.org/index.php/2013-02-07-03-02-35/2013-02-07-0303-11/1057-reit-imed/v01n01/11290-empreendedorismo-conceitos-edefinicoes.html.

CANDATEN, Deisi Mara; ZANATTA, Jocias Maier; TREVISAN, Juliana Karine Dalla-Vechia. MULHERES EMPREENDEDORAS: os desafios para equilibrar a vida pessoal e profissional. Anais do IX EGEPE - Encontro de estudos sobre empreendedorismo e gestão de pequenas empresas, p. 01-15.

DA SILVA, P. M. M.; EL-AOUAR, W. A.; DA SILVA, A. W. P.; DE CASTRO, A. B. C. B. C.; DE SOUSA, J. C. A resiliência no empreendedorismo feminino. Gestão e Sociedade, v. 13, n. 34, 1 dez. 2018.

GEM - Global Entrepreneurship Monitor Empreendedorismo no Brasil. Relatório executivo de 2018. Disponível em: https://datasebrae.com.br/wpcontent/uploads/2019/02/Relat\%C3\%B3rio-Executivo-Brasil-2018-v3-web.pdf.

REVISTA GDES EMPRESAS E GDES NEGOCIOS. Disponível em: https://revistapegn.globo.com/Mulheres-empreendedoras/noticia/2019/11/paraespecialistas-competencias-das-mulheres-nos-negocios-sao-o-futuro-dasempresas.html.

SALGADO, Carla Olinda Mendes. Componentes da resiliência organizacional. Universidade do Minho, Tese de Mestrado Mestrado em Serviços de Informação, 2013. Disponível em: http://hdl.handle.net/1822/29105.

TEIXEIRA, Michele da Silva. PERFIL DA MULHER NO MERCADO DE TRABALHO. Revista de Psicologia, Ano 6, №. 17, Julho/2012 - ISSN 19811179. Disponível em: https://idonline.emnuvens.com.br/id/article/view/195/195.

TEIXEIRA, D. M.; GAMA, M. F. F. Perfil da mulher empreendedora no município de Rondon do Pará. Il Simpósio de Produção Científica e as Interações com a Realidade Amazônica da UNIFESSPA, 2018. Disponível em: https://spc.unifesspa.edu.br/images/SPC 2018/Perfil-da-mulherempreendedora-no-municpio-de-Rondon-do-Par.pdf. 